\title{
Incidence of deep vein thrombosis and justification of chemoprophylaxis in Indian patients: A prospective study
}

\author{
Angral $\mathrm{R}^{1}$, Islam $\mathrm{MS}^{2}$, Kundan $\mathrm{S}^{3}$ \\ ${ }^{1}$ Madras Medical Mission, Chennai, India, ${ }^{2}$ Deptt. of Cardiac Surgery, National Institute of \\ Cardiovascular Diseases, Sher-e-Bangla Nagar, Dhaka, Bangladesh, ${ }^{3}$ Government Medical College, \\ Jammu, India. Email: angralr@yahoo.com
}

\begin{abstract}
Venous thromboemboilsm (VTE) is considered a major health problem in western countries necessitating thromboprophylaxis. Only a few studies are available regarding incidence in Indian patients resulting in uncertainty regarding thromboprophylaxis for our patients. In our prospective study over a period of 3 years we studied 150 patients (average age 55 years) to determine the incidence of Deep Vein Thrombosis (DVT).These patients were admitted in ICU who remained bedridden for many days and were observed for atleast four weeks. No mechanical or chemical form of deep venous thrombosis prophylaxis was used. All the patients underwent duplex ultrasonography between $7^{\text {th }}$ and $14^{\text {th }}$ postoperative day. None of the patients developed pulmonary embolism (PE). DVT developed in only 10 patients (6.6\%). In India there is much lower incidence of DVT as compared to western countries.
\end{abstract}

\section{Introduction}

VTE is a significant but relatively under diagnosed health problem. The threat of DVT and PE is daily concern in ICU/hospitalized patients. The principal goal in the approach to VTE is to prevent unnecessary deaths from P.E. Several conditions promote VTE like advanced age, obesity, fractures of pelvis and lower limb, spinal cord injuries etc. The incidence of deep vein thrombosis varies in different parts of the world for reasons that are not yet completely understood ${ }^{\mathbf{1}}$.The annual incidence of idiopathic VTE in persons $\geq 18$ years is 23 per 100000 among Caucasians, 29 per 100000 among African Americans, 14 per 100000 among Hispanics and 6 per 100000 among Asian-Pacific Islanders ${ }^{2}$.

Majorities of the studies have been conducted and published from western countries where DVT is more common whereas there is paucity of data from Indian subcontinent regarding the incidence of VTE. We therefore have to follow western literature for the guidelines on thromboprophylaxis in our patients. Though some of the recent studies published from other Asian countries have shown that DVT is not a rarity in Asian patients as was thought earlier ${ }^{3,4}$. We have undertaken this study to determine the incidence of DVT and to justify chemoprophylaxis for DVT in our patients with proximal femur fractures, total hip replacement (THR), spinal cord injuries (SCI), head injuries(HI) and major abdominal surgeries, by duplex ultrasonography having sensitivity of $>96 \%$. Combining clinical probability and USG is sensitive, specific and effective in diagnosing $\mathrm{DVT}^{5}$. These patients were admitted in ICU and many of them even remained on ventilator for many days without any mechanical or chemical prophylaxis for DVT. Even after shifting the patient from ICU, they were followed in their respective wards for observation.

\section{Materials and Methods}

After obtaining the approval of the institutional ethics committee 150 cases with proximal femur fractures, THR, SCI, HI and major abdominal surgeries were included in our prospective study carried out over a period of 3years from May 2005 to 2008 in the Deptt. of Anaesthesiology and intensive care Govt. Medical College Jammu, J\&K, India. Out of these 150 patients, 50 had proximal femur fractures, $15 \mathrm{THR}, 20 \mathrm{SCI}, 40 \mathrm{HI}$ and 25 major abdominal surgeries. There were 90 male and 60 female patients with average age 55 years (range 40-70 years). Any known risk factor associated with the occurrence of DVT like past history of DVT, obesity, malignancy, presence of varicose veins etc. was recorded. Other variables like age, sex, weight, height, presence of any medical problem etc were also documented. In those subjects with suspected DVT, a clinical 
assessment of probability can be used to determine which tests to perform (Table I) ${ }^{\mathbf{6}}$. The most studied clinical prediction rule is the Wells score ${ }^{7}$. No mechanical or chemical form of DVT prophylaxis was given.

We observed a strict protocol for mobilization of the patients following surgery; those who could be mobilized were mobilized 48 hours after surgery and who could not were passively exercised/ mobilized by the attendants. All the patients underwent duplex ultrasonographic assessment of both the lower limbs between $7^{\text {th }}$ and $14^{\text {th }}$ day. The Doppler assessment included examination of bilateral common femoral, superficial femoral, popliteal, anterior tibial and posterior tibial veins. They were assessed for flow, visualized thrombus, compressibility and augmentation. A diagnosis of DVT was made where there was visualization of thrombosis, absence of flow, lack of compressibility or lack of augmentation ${ }^{\mathbf{8}}$. The thrombus was classified as distal if it involved the calf only and as proximal if it involved the popliteal or a more proximal vein'. Patients who had both a proximal and a distal thrombus were classified as having proximal thrombosis.

The patients who developed distal DVT diagnosed by Doppler examination were not subjected to any form of thrombolytic treatment but were kept under closed clinical observation, whereas those with evidence of proximal DVT were subjected to standard thrombolytic treatment. To make sure that there was no further propagation of the thrombus, a repeat Doppler study was done in all these patents within a week of the first positive Doppler study. So the present study was conducted to determine the incidence of DVT and the need for chemoprophylaxis in our patients.

\section{Results}

Out of 150 patients DVT was detected in 10 patients ( 5 males; 5 females) with average age 51.5 years. Out of these 10 patients, only 5 patients had evidence of proximal DVT while the remaining 5 patients showed distal DVT (Table II).

The DVT positive cases were classified according to the surgical procedures carried out and the associated injuries. In our study we observed it more commonly following SCI (10\%). It was lowest in patients with HI $(2.5 \%)$ (table III). Out of 10 positive cases for DVT, only 5 had clinical signs of DVT like calf swelling and tenderness. Also, no association was found between the occurrence of DVT and body mass index (BMI) as shown in the table IV.
All the patients with evidence of DVT (both proximal and distal) underwent repeat Doppler one week after the detection of thrombus to rule out proximal extension of the thrombus. Five patients with distal DVT did not show evidence of further propagation of thrombus on repeat Doppler study. In fact, there was resolution of thrombosis in all the patients. All the 5 patients who showed the evidence of proximal DVT at the time of first Doppler examination and who were subjected to standard thrombolytic treatment did not show any propagation of thrombus. None of the patients developed clinically evident P.E. while in hospital or during first six weeks following surgery or hospitalization.

Table I: Criteria proposed by Wells et al (1995) for calculating the risk of $\mathrm{DVT}^{6}$

\begin{tabular}{|c|c|c|c|c|}
\hline & \multicolumn{3}{|c|}{ Clinical feature } & Score \\
\hline 1 & \multicolumn{3}{|c|}{ Active cancer within 6 months } & 1 \\
\hline 2 & \multicolumn{3}{|c|}{ Paralysis, paresis, or cast of lower extremity } & 1 \\
\hline 3 & \multicolumn{3}{|c|}{$\begin{array}{l}\text { Recently bedridden }>3 \text { days or major surgery within } 4 \\
\text { weeks }\end{array}$} & 1 \\
\hline 4 & \multicolumn{3}{|c|}{ Entire leg swollen } & 1 \\
\hline 5 & \multicolumn{3}{|c|}{$\begin{array}{l}\text { Calf diameter }>3 \mathrm{~cm} \text { larger than opposite leg at } 10 \mathrm{~cm} \\
\text { below the tibial tuberosity }\end{array}$} & 1 \\
\hline 6 & \multicolumn{3}{|c|}{ Localised tenderness along deep vein system } & 1 \\
\hline 7 & \multicolumn{3}{|c|}{ Pitting oedema } & 1 \\
\hline 8 & \multicolumn{3}{|c|}{ Collateral superficial veins (non- varicose) } & 1 \\
\hline 9 & \multicolumn{3}{|c|}{$\begin{array}{l}\text { Alternative diagnosis as more than or equal likely than } \\
\text { that of DVT }\end{array}$} & 2 \\
\hline \multicolumn{5}{|c|}{ Pretest probability for DVT based upo } \\
\hline & Score & Probability & \multicolumn{2}{|c|}{ Frequency of DVT(\%) } \\
\hline & 0 & Low & \multicolumn{2}{|c|}{03} \\
\hline & $1-2$ & Medium & \multicolumn{2}{|l|}{17} \\
\hline & $>=3$ & High & \multicolumn{2}{|l|}{75} \\
\hline
\end{tabular}

Table II: Distribution of thrombus in the lower limb veins detected by duplex ultrasonography $(\mathrm{n}=10)$

\begin{tabular}{llccccc}
\hline $\begin{array}{c}\text { Sex/ } \\
\text { age } \\
\text { (yrs) }\end{array}$ & $\begin{array}{c}\text { Cases (DVT } \\
\text { Positive) }\end{array}$ & $\begin{array}{c}\text { Ant. } \\
\text { tibial } \\
\text { vein }\end{array}$ & $\begin{array}{c}\text { Post. tibial } \\
\text { vein }\end{array}$ & $\begin{array}{c}\text { Popliteal } \\
\text { vein }\end{array}$ & $\begin{array}{c}\text { Superf. Common Calf } \\
\text { femoral } \\
\text { vein }\end{array}$ & $\begin{array}{c}\text { femoral } \\
\text { vein }\end{array}$ \\
\hline F/52 & Proximal femur \# & + & & & & + \\
M/45 & Proximal femur \# & + & & & & + \\
M/50 & S.C.I & & & + & + & \\
F/58 & Proximal femur \# & & & + & & \\
F/62 & Proximal femur \# & & & + & & + \\
F/54 & S.C.I & & + & + & & \\
F/68 & THR & & & + & + & + \\
M/35 & H.I & + & & & & + \\
M/58 & Major abd. Surgery & + & & & & + \\
\hline M/64 & Major abd. Surgery & + & & & & + \\
\hline
\end{tabular}

Table III: Occurrence of DVT

\begin{tabular}{lc}
\hline Total(150) & No. of DVT positive cases(10) \\
\hline Proximal femoral fracture & $4(8 \%)$ \\
THR & $1(6.6 \%)$ \\
Major abdominal surgery & $2(8 \%)$ \\
HI & $1(2.5 \%)$ \\
SCI & $2(10 \%)$ \\
\hline
\end{tabular}


Table IV: Body mass index

\begin{tabular}{lcc}
\hline & $\begin{array}{c}\text { Patient population } \\
(\mathrm{n}=150)\end{array}$ & $\begin{array}{c}\text { DVT positive } \\
\text { cases }(\mathrm{n}=10)\end{array}$ \\
\hline Range & $18.8-31.5$ & $19.8-28.1$ \\
Average & 23.9 & 23.6 \\
\hline
\end{tabular}

\section{Discussion}

Due to paucity of published data from Asian subcontinent, until recently, DVT following lower limb or major abdominal surgeries, SCI and $\mathrm{HI}$ was considered to be a rarity in Asian patients unlike western countries. Dhillon et al. in a prospective study of 88 patients from Singapore without any prophylaxis, reported that $62.5 \%$ of the patients demonstrated venographic evidence of $\mathrm{DVT}^{3}$. Ko et al. in a prospective study of 80 'low-risk' Chinese patients undergoing total knee arthroplasty (TKA) and total hip arthroplasty (THA) showed 27-31\% incidence of post operative DVT detected by duplex sonography ${ }^{10}$. Both the studies suggested that the present practice of withholding routine prophylaxis against thromboembolism in Asian patients labeled 'high-risk' should be reconsidered.

In our study, we have observed that out of 150 patients, 10 demonstrated sonographic evidence of DVT, out of which 5 patients $(3.3 \%)$ had a proximal DVT and 5 patients (3.3\%) had a distal DVT. There was not a single case of P.E. These results were comparable to those published by Jain et al. who reported a very low incidence of DVT following TKA and THA in Indian patients, only two patients in their series of 106 patients from Northern India showed duplex sonographic evidence of proximal DVT ${ }^{11}$ and with those published by Bagaria et al. who reported $6.12 \%$ incidence of DVT and $0.6 \%$ incidence of P.E. in their prospective study of 147 patients undergoing major orthopedic surgery of lower limb without any prophylaxis ${ }^{12}$. Our results are also in accordance with the study done by Mavalankar et al. who reported that DVT was detected in only nine patients out of 125 by duplex ultrasonography. Out of these nine patients, only three patients had evidence of proximal DVT while the remaining six patients showed distal $\mathrm{DVT}^{\mathbf{1 3}}$. All these authors concluded that DVT has a lower incidence in Indian patients as compared with other ethnic groups. Our results, however, are not in agreement with those published by Agarwala et al. who reported 60\% incidence of DVT in their patients not receiving any form of chemoprophylaxis. $83 \%$ of these patients had distal DVT and there was not a single case of P.E ${ }^{14}$. This difference could be because of the difference in the diagnostic modality used in the both studies. While Agarwala et al. used contrast venography, which is the gold standard, for diagnosis of both proximal and distal DVT; we employed duplex sonography for detection of DVT. Though this is an established diagnostic modality, many authors have questioned its ability to diagnose asymptomatic calf thrombi as it may miss $20 \%$ of isolated calf $\mathrm{DVT}^{\mathbf{1 5}}$. So, isolated calf thrombi in some of the patients may not have been picked up by Doppler examination in our study.

Though age is uncertain as a risk factor, we found an increasing evidence of thrombosis with greater age. All our DVT positive patients were in the age group of 35-68 years (mean age 54.6 years). None of the patients had a known risk factor for the development of DVT.

We did not find any correlation between the presence of clinical signs of thrombosis and sonographic evidence of DVT. Out of 10 , only 5 patients had clinical features suggestive of DVT. This confirms unreliability of physical signs in the diagnosis of DVT as shown by Stulberg et al. ${ }^{16}$. We also observed that DVT developed more commonly in SCI patients as compared to other patients of our study. As the paralyzed limb lies immobile and loses the vascular tone resulting in stasis, the SCI patients are supposed to be at a higher risk of developing DVT ${ }^{17}$. Occurrence of DVT was lowest in the patients with $\mathrm{HI}$.

As 5 out of 10 patients had distal DVT we decided not to treat them with anticoagulation. Kakkar et al. have shown that popliteal and femoral clots are precursors to P.E, this is in sharp contrast to tibial and peroneal clots, which are of little clinical significance with respect to symptomatic emboli ${ }^{\mathbf{1 8}}$. Many other authors have also recommended treating asymptomatic distal DVT by closed clinical observation and serial Duplex ultrasound study ${ }^{19}$.

From a demographic view point, Asians and Hispanic population have a lower risk of VTE, whereas white and blacks have a higher risk (2.5-4 times higher) which may relate to a lower prevalence of genetic factors predisposing to VTE, such as factor V leiden in Asians population (0.5\%) compared with Caucasians $(5 \%)^{20}$. The difference in VTE incidence may be related to less efficient inactivation of coagulation by activated protein $\mathrm{c}$ or less fibrinolytic activity among Caucasians ${ }^{3}$. Some reports have described a higher incidence of fatal $\mathrm{PE}$ during winter months ${ }^{21}$. Assuming the physical activity in population decrease in the winter, it is possible that this finding demonstrate an inverse relationship between physical activity and development of $\mathrm{VTE}^{22}$. DVT is rare in societies where diet is primarily based on unrefined plant foods, rather than on animal products or highly 
refined foods ${ }^{23}$. Low fiber intake is associated with higher activity of plasminogen activator inhibitor ,the body's main inhibitor of fibrinolysis ${ }^{24}$. So the low incidence could be the genetic factor, environmental factors or may be low socioeconomic status of our rural patients leading to a lower consumption of a fat- rich diet, the warmer climatic conditions or the practice of massage and passive exercises by the attendants. The reported incidence of DVT could also be because of the lack of awareness among the doctors and the patients, and of diagnostic facilities in this part of the world, thus many of the cases remain undiagnosed $^{17}$.

Low molecular weight heparin (LMWH) which is currently recommended being one of the preferred drugs for thromboprophylaxis has many potential disadvantages like increase in the total cost of treatment and bleeding complications. McNally et al. have also stated increased incidence of bleeding complications like excessive bruising around the wound and increased wound bleeding or haematomas with the use of LMWH which has prevented their routine use in joint replacement, as was the case with unfractionated heparin in the past $^{25}$.

Mechanical prophylaxis against DVT has attracted less interest although it is a method which is easy to control and devoid of risk. It has been demonstrated by several investigators that passive movements at the ankle joint and intermittent compression of the calf constitute effective prophylaxis ${ }^{26}$. Inferior vena cava filters are used on presumption that they reduce pulmonary embolism, though their effectiveness and safety profile is not well established $^{27}$. In general their use is restricted to certain high risk situations until more information becomes available, they are recommended in those with a contradiction to anticoagulants; but not in addition to anticoagulants unless an individual with a risk of bleeding, develops acute proximal $\mathrm{DVT}^{7}$.

We, therefore, wonder how far we are justified in subjecting all the patients in our study to routine chemoprophylaxis which could increase the risk of complications and put more burdens on the already stretched financial resources of the patient. From our study and those by other Indian authors, it appears that DVT and P.E. in Indian patients is a low incidence problem.

Conclusion: We believe that there is enough evidence in the Western literature to advocate routine thromboprophylaxis, there is not yet enough evidence to justify the same for the Indian patients though it is not perhaps appropriate to make any definite recommendations about chemoprophylaxis only on the basis of our research and we strongly advocate that use of pharmacological prophylaxis should be only for the high risk patients in whom the potential benefits clearly appear to outweigh the risk. However, a close clinical monitoring with a high level of suspicion of DVT and PE, should be exercised. Duplex sonography should be preferably carried out on all the high risk patients and a repeat ultrasonography should be performed on all the positive patients to rule out proximal migration of the thrombus.

\section{References}

1. Coon WW.Epidemiology of venous thromboembolism. Ann Surg 1977; 186: 149-64.

2. White RH, Zhou H, Romano PS. Incidence of idiopathic deep vein thrombosis and secondary thromboembolism among ethnic groups in California. Ann Inter Med 1998; 128: 737-740.

3. Dhillon KS, Askander A, Doraisamy S. Postoperative deep vein thrombosis in Asian patients is not a rarity: A prospective study of 88 patients with no prophylaxis. J Bone Joint Surg Br 1996; 71: 427-30.

4. Nathan S, Aleem MA, Thiagaranjan P, Das D.S. The incidence of proximal deep vein thrombosis following total knee arthroplasty in an Asian population: a Doppler ultrasound study. J orthop. Surg (Hong Kong) 2003; 11: 184-9.

5. Perone N, Bounameaux H, Perrier A. Comparison of four strategies for diagnosing deep vein thrombosis: A cost effective analysis. Am J Med. 2001; 110:33-40.

6. Wells PH, Hirsh J, Anderson DR, et al. Accuracy of clinical assessment of DVT. Lancet 1995; vol. 345: 1326-30.

7. Guyatt GH, Aki EA, Crowther M, Gutterman DP, Schwnemann HJ. Executive summary: A ntithrombotic therpy and prevention of thrombosis, 9 ed: American college of chest physicians evidence-based clinical practice guidelines. Chest $2012 \mathrm{Feb} ; 141$ (2 suppl):7s$47 \mathrm{~s}$.

8. Birdwell BG, Raskob GE, Whitseth TL et al. The clinical validity of normal compression ultrasonography in outpatients suspected of having deep vein thrombosis. Ann. Intern Med 1998; 128:1-7.

9. Cogo A, Lensing AWA, Prandoni P, Hirsh J. Distribution of thrombosis in patient with symptomatic deep-vein thrombosis: implication for simplifying the diagnostic process with compression ultrasound. Arch Intern Med 1993; 153: 2777-80.

10. Ko PS, Chan WF, Siu TH, Khoo J, Wu WC, Lam JJ. Deep venous thrombosis after total hip or knee arthroplasty in a"low-risk" Chinese population. J Arthroplasty 2003;18:174-9.

11. Jain V, Dhaon BK, Jaiswal A, Nigam V, Singla J. Deep vein thrombosis after total hip and knee arthroplasty in Indian patients. Postgrad Med J 2004;80:729-31. 
12. Bagaria V, Modi N, Panghate A, Vaidya S. Incidence and risk factors for development of VTEin Indian patients undergoing major orthopaedic surgery: Results of a prospective study. Postgrad Med J 2006;82:136-9.

13. Mavalankar AP, et al. Routine chemoprophylaxis for DVT in Indian patients: Is it really justified? Indian Journal of Orthopaedics 2007; 41: 188-93.

14. Agarwala S, Bhagwat AS, Modhe J. Deep vein thrombosis in Indian patients undergoing major lower limb surgery. Indian J Surg 2003; 65: 159-62.

15. Comerota AJ, Katz ML, Hashemi HA. Venous duplex imaging for the diagnosis of acute venus thrombosis. Haemostasis 1993; 23: 61-71.

16. Stulberg BN, Insall JN, William GW, Ghelman B. Deep vein thrombosis following total knee replacement: An analysis of six hundred and thirty eight arthroplasties.J Bone Joint Surg Am 1984; 66: 194-201.

17. Saraf SK, Rana RJ, Sharma OP. VTEin acute spinal cord injury patients. Indian Journal of Orthopaedics 2007; 41:194-7.

18. Kakkar W, Howe CT, Flanc C, Clarke MB. Natural history of postoperative deep vein thrombosis.Lancet 1969; 2: 230-2.

19. Sharpe RP, Gupta R, Gracias VH, Pryor JP, Pieracci FM, Reilly PM, et al. Incidence and natural history of below-knee deep venous thrombosis in high-risk trauma patients. J Trauma 2002; 53: 1048-52.
20. Gregg JP, Yamane AJ, Grody WW. Prevalence of factor V-Leiden mutation in four distinct American ethnic populations. Am J Med Genet 1997; 73: 334336.

21. Wroblewski BM, Siney P, White R. Seasonal variation in fatal pulmonary embolism after hip arthroplasty. Lancet 1990; 335: 56.

22. Boulay F, Berthier F, Schoukroun G et al. Seasonal variation in hospital admission for deep vein thrombosis and pulmonary embolism: analysis of discharge data. BMJ 2001; 323: 601-602.

23. Burkitt DP, Walker AR, Painter NS. Dietary fiber and disease. JAMA 1974; 229: 1068-1074.

24. Boman K,Hellsten G, Bruce A, Hallmans G, Nilsson TK .Endurance physical activity, diet and fibrinolysis. Atherosclerosis 1994; 106: 65-74.

25. MacNally MA, Cooke EA, Harding ML, Mollan RA. Attitudes to and utilization of, low molecular weight heparins in joint replacement surgery. J R Coll Surg Edinb 1997;42:407-9.

26. $\mathrm{T}$ Scherff Sorensen, $\mathrm{J}$ Jorgensen. Mechanical prophylaxis against deep vein thrombosis in Charley Hip Arthoplasty. Acta Orthopaedica 1981;52(1):69-72.

27. Young T, Jang H, Hughas R. Vena caval filters for the prevention of pulmonary embolism. Cochrane Database Sys Rev. 2010 Feb; 17(2): CD006212. 